Supporting Information

\title{
Electrochemical and Transport Properties of Ions in Mixtures of Electroactive Ionic Liquid and Propylene Carbonate with a Lithium Salt for Lithium-ion Batteries
}

Bruno Gélinas, Myriann Natali, Thomas Bibienne, Lily Li, Michaël Dollé and Dominic

$$
\text { Rochefort }{ }^{*}
$$

Département de chimie, Université de Montréal, CP6128 Succ. Centre-Ville, Montréal, Québec, Canada H3C 3J7

*Corresponding author: Tel: +1-514-343-6733, Fax: +1-514-343-7586, email: dominic.rochefort@umontreal.ca

\section{List of Content:}

- Synthetic procedure of Lithium Ferricenyl(trifluoromethylsulfonyl)imide

- Summary of self-diffusion analysis

- Viscosity measurements

- Electrochemical analysis and additional figures

- $\quad \mathrm{LiTi}_{2}\left(\mathrm{PO}_{4}\right)_{3}$ preparation and X-Ray diffraction 
Synthetic procedure of Lithium Ferrocenylsulfonyl(trifluoromethylsulfonyl)imide (Li [FcNTf]) in two step procedure.

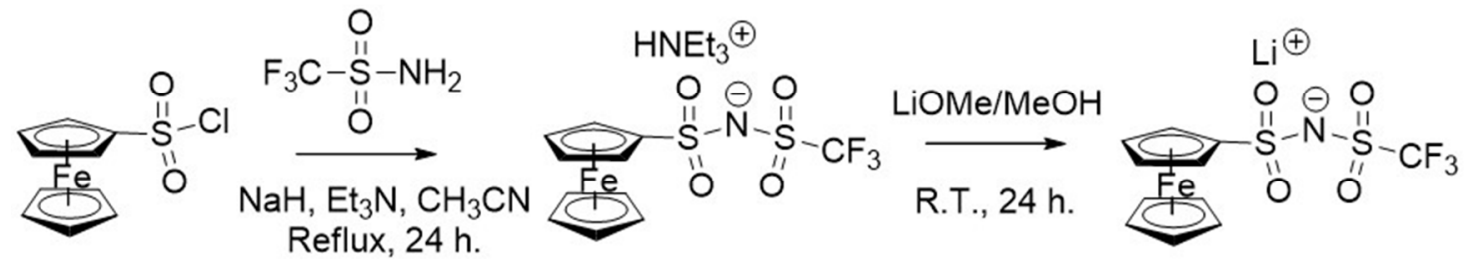

Figure S1. Synthetic pathway of Lithium Ferrocenylsulfonyl (trifluoromethylsulfonyl)imide (Li [FcNTf])

Sodium hydride ( 1 eq., $60 \%$ dispersion in oil) was placed in a round-bottom flask under argon atmosphere and placed in ice bath. Trifluoromethanesulfonamide (1 eq.) was dissolved in acetonitrile and was cautiously added dropwise to sodium hydride. The solution was stirred during 10 minutes at $0{ }^{\circ} \mathrm{C}$. A slow addition of ferrocenylsulfonyl chloride (1 eq.) was then made and trimethylamine (1.15 eq.) was also added. The resulting solution was stirred and heated at reflux temperature for 24 hours. The brown solution was filtered and the precipitate was washed with acetone to achieve a white precipitate. Removal of the solvent under reduced pressure produced a brown oil and the oil was washed with diethyl ether to remove the unreacted ferrocenylsulfonyl chloride. Dichloromethane was used to dissolve the oil, the organic phase was washed with $1.0 \mathrm{M}$ $\mathrm{HCl}$ aqueous solution and dried over $\mathrm{MgSO}_{4}$. The triethylammonium ferrocenylsulfonyl(trifluoromethylsulfonyl)imide ([ $\left.\left.\mathrm{Et}_{3} \mathrm{HN}\right][\mathrm{FcNTf}]\right)$ was dried overnight under reduce pressure at room temperature and enough pure to be directly used in the next procedure. [ $\left.\mathrm{Et}_{3} \mathrm{HN}\right]$ [FcNTf] was dissolved in methanol and lithium methoxide (2 eq.) was added. The mixture was stirred during $24 \mathrm{~h}$. at room temperature and the solvent was then removed under vacuum. The lithium salt was extracted with diethyl ether and the solution was filtered over filter agent Celite. The solvent was removed under vacuum, Li [FcNTf] was triturated by methyl tert-butyl ether to remove coordinated diethyl ether and the brown-yellow salt was dried overnight under reduce pressure at $80^{\circ} \mathrm{C} .{ }^{1} \mathrm{H}$ NMR $\left(\right.$ DMSO-d $\left._{6}, 300 \mathrm{MHz}\right): \delta(\mathrm{ppm})=4.53(\mathrm{t}, 2 \mathrm{H}), 4.28(\mathrm{~s}, 7 \mathrm{H}) .{ }^{19} \mathrm{~F}$ NMR $\left(\right.$ DMSO-d $_{6}, 282$ $\mathrm{MHz}): \delta(\mathrm{ppm})=-79.06 .{ }^{13} \mathrm{C}$ NMR $\left(\right.$ DMSO-d $\left._{6}, 125 \mathrm{MHz}\right): \delta(\mathrm{ppm})=122.74 ; 118.43$; 
94.57; 70.42; 69.18; 68.59. (ESI) $\mathrm{m} / \mathrm{z}:\left[\mathrm{M}^{*}{ }^{-}\right]\left(\right.$calcd for $\left.\mathrm{C}_{11} \mathrm{H}_{9} \mathrm{~F}_{3} \mathrm{FeNO}_{4} \mathrm{~S}_{2}{ }^{-}\right): 395.928$ Found: 395.926. 
$\underline{\text { Summary of self-diffusion analysis }}$
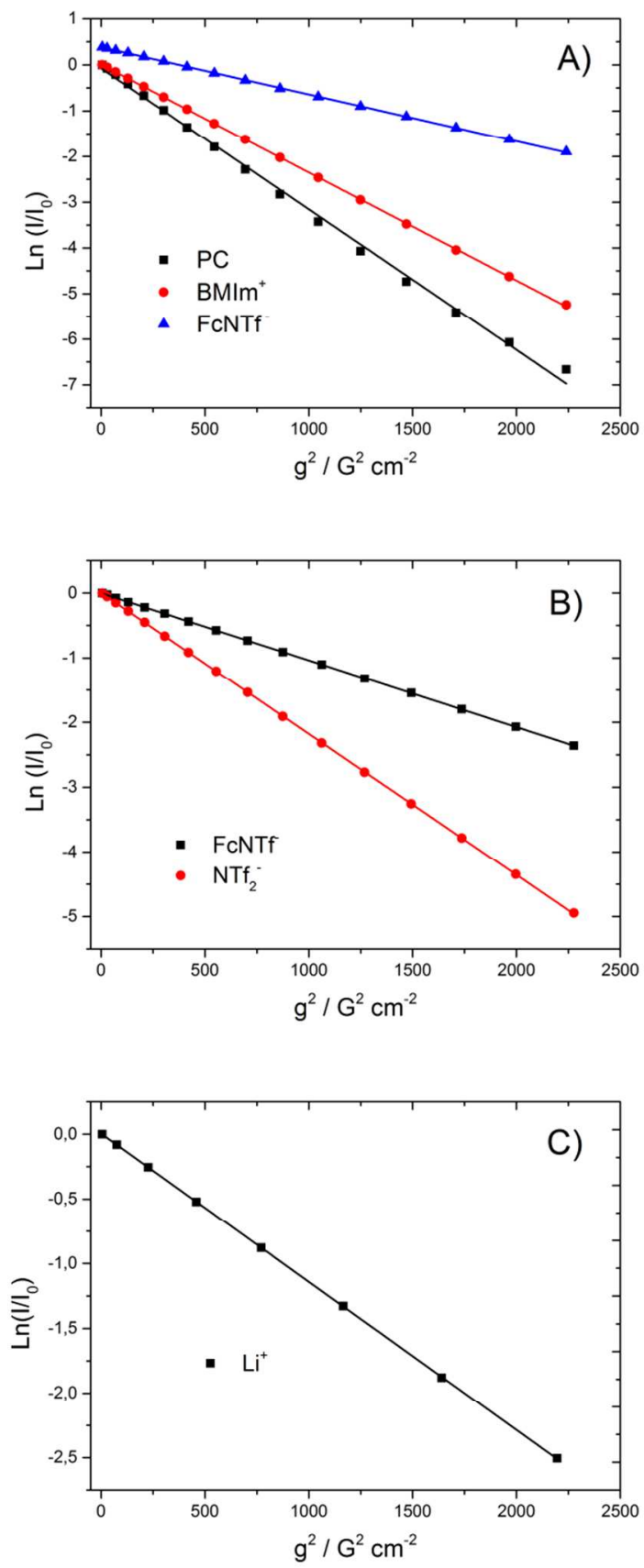

Figure S2. Stejskal-Tanner plots $\left(\mathrm{Ln}\left(\mathrm{I} / \mathrm{I}_{0}\right)\right.$ vs $\left.\mathrm{g}^{2}\right)$ of $0.3 \mathrm{M}$ of [BMIm] [FcNTf] with $1.0 \mathrm{M}$ LiNTf $_{2}$ in pure PC using A) $\left.{ }^{1} \mathrm{H}, \mathrm{B}\right){ }^{19} \mathrm{~F}$ and C) ${ }^{7} \mathrm{Li}$ NMR.

\section{$\underline{\text { Viscosity measurements }}$}




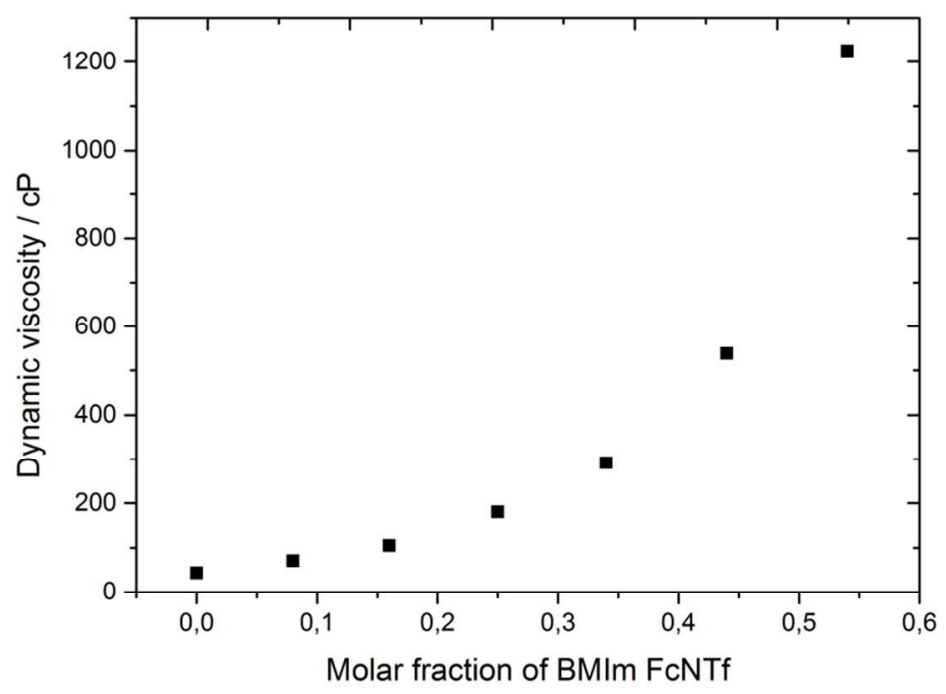

Figure S3. Dynamic viscosity as a function of molar fraction of [BMIm] [FcNTf] in Neat IL 


\section{Electrochemical analysis and additional figures}
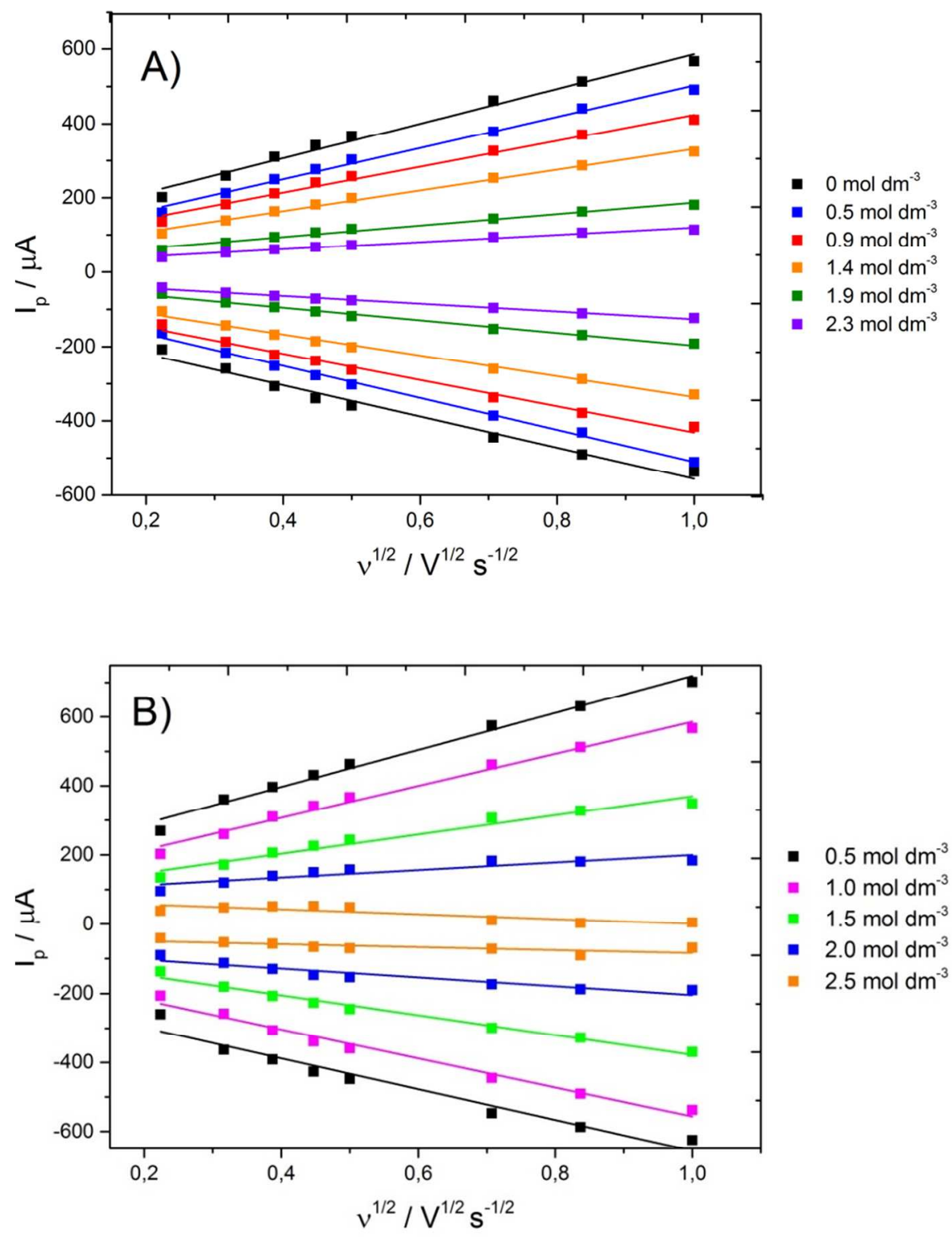

Figure S4. A) Randles-Sevcik plots $\left(\mathrm{I}_{\mathrm{p}} \mathrm{vs} \mathrm{v}^{1 / 2}\right.$ ) of $0.3 \mathrm{M}$ of [BMIm] [FcNTf] with $1.0 \mathrm{~mol}$ $\mathrm{dm}^{-3} \mathrm{Li}\left[\mathrm{NTf}_{2}\right]$ in PC using various concentrations of [BMIm] [NTf 2 . B) Randles-Sevcik

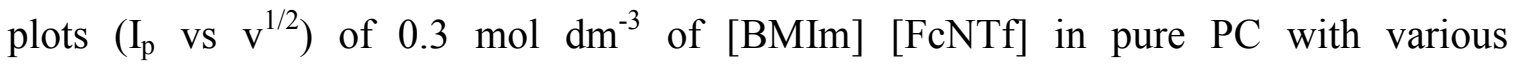
concentrations of $\mathrm{Li}\left[\mathrm{NTf}_{2}\right]$. The scan rates used were 50 to $1000 \mathrm{mV} \mathrm{s}^{-1}$. 


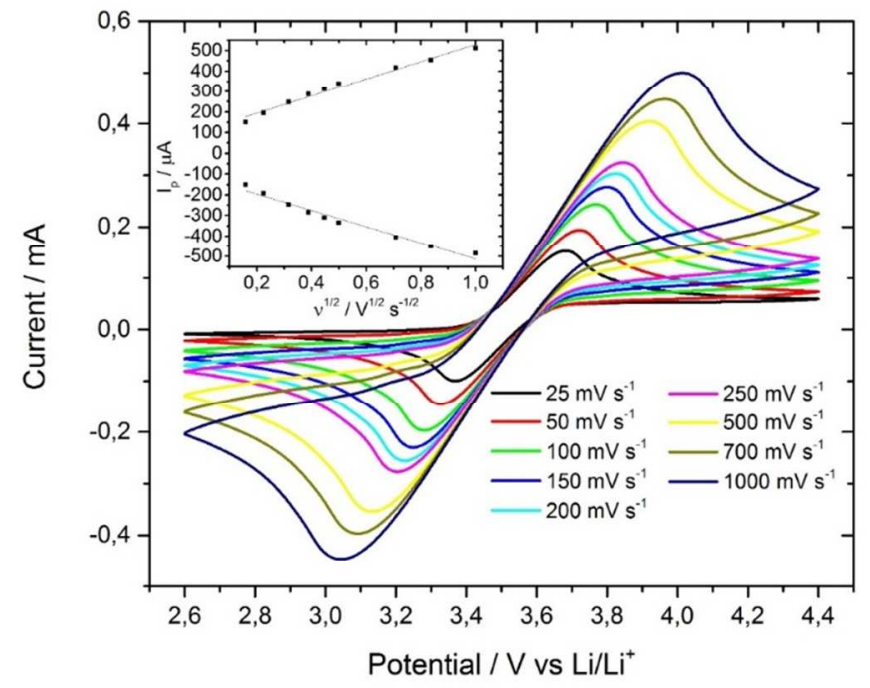

Figure S5. CVs and Randles-Sevcik plots $\left(\mathrm{I}_{\mathrm{p}} \mathrm{vs} \mathrm{v}^{1 / 2}\right) 0.3 \mathrm{~mol} \mathrm{dm}^{-3}$ of Li [FcNTf] with 0.7 $\mathrm{mol} \mathrm{dm} \mathrm{d}^{-3}$ of $\mathrm{Li}\left[\mathrm{NTf}_{2}\right]$ in PC. The scan rates used were 25 to $1000 \mathrm{mV} \mathrm{s}^{-1}$.

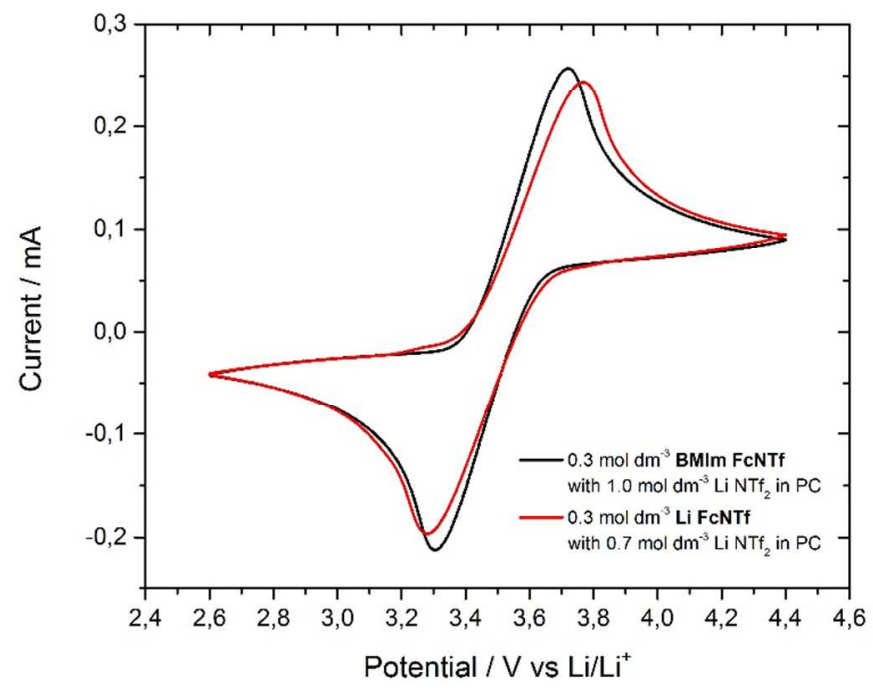

Figure S6. CVs of $0.3 \mathrm{~mol} \mathrm{dm}^{-3}$ of [BMIm] [FcNTf] with $1.0 \mathrm{~mol} \mathrm{dm}^{-3}$ of Li [NTf ${ }_{2}$ ] in PC (Electrolyte 2; black line) and $0.3 \mathrm{~mol} \mathrm{dm}^{-3}$ of Li [FcNTf] with $0.7 \mathrm{~mol} \mathrm{dm}^{-3}$ of Li [NTf 2 ] in PC (Electrolyte 3; red line) at $100 \mathrm{mV} \mathrm{s}^{-1}$. 


\section{$\left.\underline{\mathrm{LiTi}_{2}} \underline{\mathrm{PO}}_{4}\right)_{3}$ preparation and X-Ray diffraction}

Synthesis of $\operatorname{LiTi}_{2}\left(\mathrm{PO}_{4}\right)_{3}(\mathrm{LTP}) . \mathrm{Li}_{2} \mathrm{CO}_{3}, \mathrm{NH}_{4} \mathrm{H}_{2} \mathrm{PO}_{4}$ (MAP) and $\mathrm{TiO}_{2}$ were used as precursors, stirred in $50 \mathrm{~mL}$ of water for 2 hours. Then, the liquid media was completely evaporated using hot plate. Then, the remained powder was calcined at $900{ }^{\circ} \mathrm{C}$ for 12 hours. Finally, a size reduction was performed using a continuous-flow agitator wet mill (Netszch Microcer) to obtain submicron-sized particles. The milling process includes preparing a 4 wt. \% of LTP in isopropyl alcohol (IPA). This mixture was then flowing through the mill containing yttria-stabilized zirconia beads with size of $0.5 \mathrm{~mm}$. Besides, 11 wt. \% of $\beta$-lactose (Acros Organics) was added as the source of carbon. The milling process was carried out for $2 \mathrm{~h} 30$ at a speed of $2200 \mathrm{RPM}$. Then, the slurry was collected from the mill and dried on a hot plate until evaporation of IPA. Finally, the dry powder was heated up at $700{ }^{\circ} \mathrm{C}$ for 2 hours in a $\mathrm{N}_{2}$ atmosphere.

X-Ray diffraction (XRD) of LTP. XRD patterns were recorded on a Philips X-ray spectrometer, using $\mathrm{Cu} \mathrm{K} \alpha$ radiationXRD measurements were collected in steps of $0.02^{\circ}$ in $2 \theta$ range of $10-80^{\circ}$. The unit cell parameters were determined by pattern matching using FullProf suite program.The X-Ray diffraction pattern of LTP is presented in Figure S7. It can be indexed in the R-3C rhombohedral space group with $\mathrm{a}=8.48 \AA$ and $\mathrm{c}=$ $20.84 \AA$, as shown on Figure S7. One extra peak is observed at $38.5^{\circ}$ (highlighted by a star) and is attributed to the main diffraction peak (111) of the Al sample holder . 


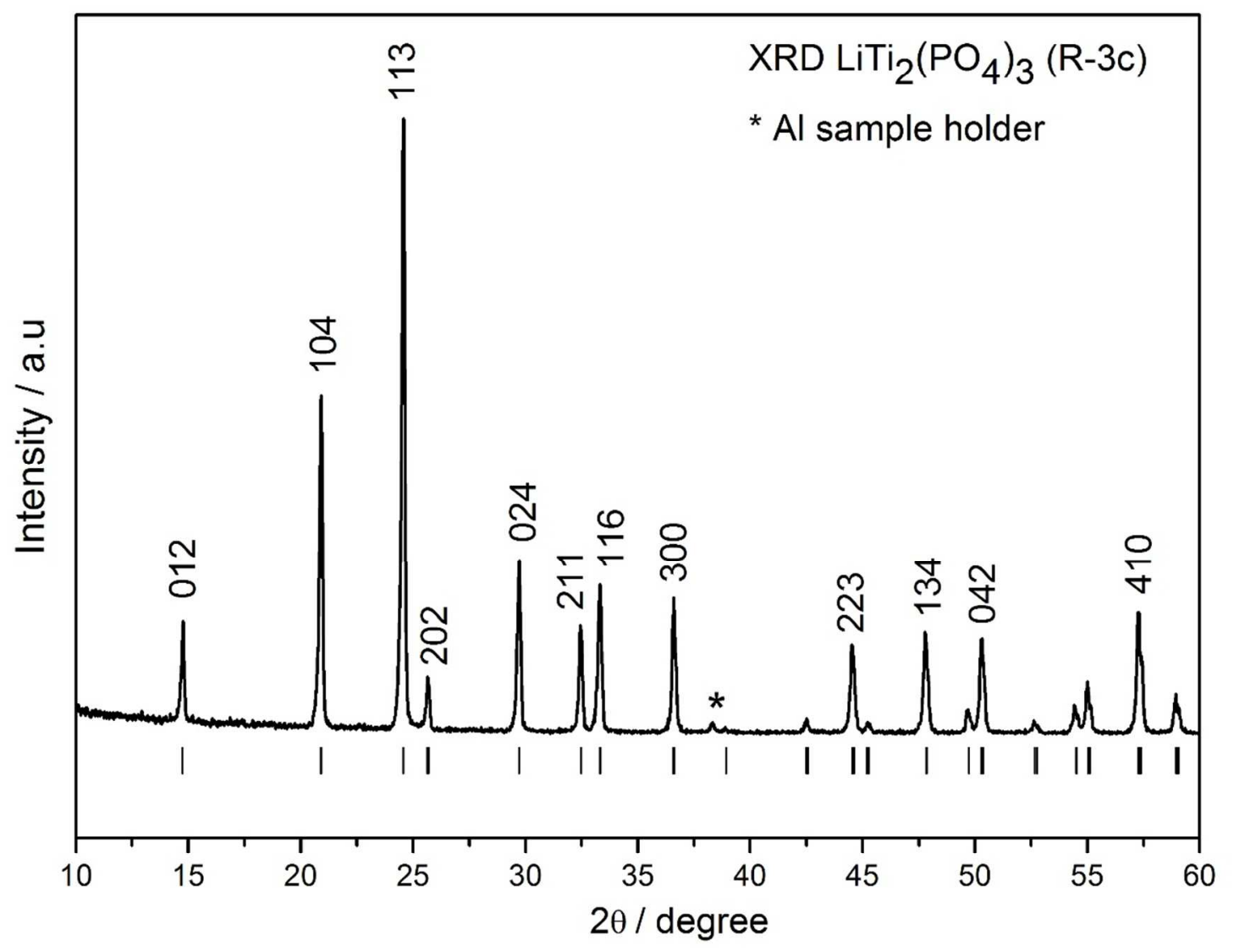

Figure S7. X-Ray diffraction (XRD) of $\mathrm{LiTi}_{2}\left(\mathrm{PO}_{4}\right)_{3}$ (LTP), with R-3c space group indexation. The star $(*)$ refers to the $\mathrm{Al}$ sample holder. 